\title{
Changes in the Profile of Lipoprotein Subfractions Associated with Hormone Replacement Therapy
}

\author{
José Luiz da Costa Vieira, Marcos Emanuel W. Gomes, Áurea Beltrão de Almeida, \\ Emílio H. Moriguchi
}

Porto Alegre, RS - Brazil

\begin{abstract}
Objective - To report the effects of 2 regimens of hormone replacement therapy during the postmenopausal period on the profile of the major lipoprotein subfractions (HDL, LDL, and $V L D L)$.
\end{abstract}

Methods - We carried out a cohort study in 38 postmenopausal patients who were starting their hormone replacement therapy due to gynecological indications, for a period of 12 weeks. Analysis of lipoprotein subclasses was performed through nuclear magnetic resonance spectroscopy.

Results - Hormone replacement therapy cause an increase in the proportion of larger subfractions of VLDL and $H D L(p=0.008$ and 0.03 , respectively) and in the proportion oflarger particles of $V L D L$ due to a $36 \%$ increase in the levels of larger particles $(p=0.004)$, concomitantly with a $15 \%$ reduction in the levels of smaller particles $(p=0.04)$. In regard to $H D L$, the increase occurred only a $17 \%$ increase in the levels of larger particles $(p=0.002)$. No significant change occurred in the distribution pattern of $L D L$ subfractions.

Conclusion - The proportion of larger subfractions of $V L D L$ and HDL increases after hormone replacement therapy. The increase in the proportion of larger particles of $V L D L$ occurs due to an increase in the levels of the larger subclasses concomitantly with a reduction in the smaller particles. However, an increase in the proportion of larger particles of HDL occurs only due to an increase in the levels of the larger subfractions.

Key words: lipoproteins, hormone replacement therapy, coronary heart disease

Instituto de Cardiologia do Rio Grande do Sul/Fundação Universitária de Cardiologia - Porto Alegre

Mailing address: Jose Luiz da Costa Vieira - Rua Coraci Prates da Veiga, 73 94410-290 - Viamão, RS, Brazil

English version by Stela Maris C. Gandour
Despite the evidence, at the present time challenged by the results of the first 2 randomized clinical trials of secondary prevention in ischemic heart disease ${ }^{1,2}$, that estrogen may protect against coronary heart disease, the method by which this protective effect can be mediated has never been properly explained. Among the proposals, the estrogen impact on the lipid profile has always been highlighted, with a reduction in LDL-cholesterol and an increase in HDL-cholesterol. However, some studies have shown that only $25 \%$ to $50 \%$ of risk reduction could be attributed to this change ${ }^{3-5}$. In the last decade, addition of progestin has been routinely recommended in postmenopausal hormone replacement to reduce the risk of endometrial carcinoma induced by estrogen ${ }^{6}$. In observational studies ${ }^{7-9}$, this practice seems not to have attenuated the cardioprotective effect of postmenopausal estrogen therapy.

In recent years, has gained relevance that each group of lipoproteins - high density lipoprotein (HDL), low density lipoprotein (LDL), and very low density lipoprotein (VLDL)is formed by very heterogeneous and different particles in their association with coronary heart disease ${ }^{10-12}$. Based on this, increasing importance has been attributed to the influence of the distribution pattern of subfractions of each of these major lipoproteins in coronary risk. Therefore, individuals with similar serum levels of LDL-cholesterol and HDLcholesterol may also have very different levels of risk for coronary heart disease because of differences in the distribution of subclasses. Currently, evidence exists that for a certain level of LDL-cholesterol, patients with a profile of lipoprotein subclasses in which small and dense LDLs (pattern B) predominate have a substantially higher risk of developing coronary heart disease and acute myocardial infarction than those patients in whom large and floating LDLs (pattern A) predominate ${ }^{10-14}$. Likewise, subclasses of HDL measured by electrophoresis show a striking difference in their associations with coronary heart disease, as follows: the 3 largest subclasses $\left(\mathrm{HDL}_{2 \mathrm{~b}}, \mathrm{HDL}_{2 \mathrm{a}}\right.$, and $\mathrm{HDL}_{3 \mathrm{a}}$ ) show the expected inverse correlation with progression and seve- 
rity of the disease, but the 2 smallest subclasses $\left(\mathrm{HDL}_{3 \mathrm{~b}}\right.$ and $\mathrm{HDL}_{3 \mathrm{c}}$ ) show a positive correlation ${ }^{15,16}$.

Only some studies considered the possibility that the cardioprotective mechanism of postmenopausal hormone replacement therapy could also be mediated by changes imposed on the profile of these subfractions ${ }^{17-19}$.

We report a cohort study aiming to assess the effects of an estrogen-progestin replacement regimen and another of estrogen replacement, classically used in the period following menopause, on the distribution of the subfractions of the major lipoproteins - HDL, LDL, and VLDL. These subfractions were determined by nuclear magnetic resonance to test the hypothesis that hormone replacement therapy may lead to a less atherogenic distribution profile of the lipoprotein subfractions.

\section{Methods}

We carried out a cohort study on postmenopausal patients from the Outpatient Care Clinics of Climacterium of the Gynecological Service of the Irmandade da Santa Casa de Misericórdia de Porto Alegre, who had gynecological indication for initiating hormone replacement therapy. Postmenopausal patients of any age referred to the ambulatory clinics due to symptoms of climacterium or for treatment or prevention of osteoporosis were accrued. After complete gynecological assessment, including mammography and endometrial evaluation, these patients were referred for hormone replacement therapy during the period from July '97 to December ' 97 . Two regimens of hormone replacement were used out of those usually employed in the outpatient clinics. The regimens comprised equine conjugated estrogens at the dosage of $0.625 \mathrm{mg}$ associated with $2.5 \mathrm{mg}$ of medroxyprogesterone (Premelle ${ }^{\circledR}$ ), administered daily in a continuous way for those patients with an intact uterus, and equine conjugated estrogens at the dosage of $0.625 \mathrm{mg}$ daily (Premarin 0.625®) used isolated for hysterectomized patients. Patients on isolated or combined estrogen therapy who effectively used the medication for more than $75 \%$ of the days were enrolled in the same group (group of hormone replacement therapy) because, after the statistical analysis, no difference was found between the 2 forms of therapy in regard to repercussions on the profile of distribution of the subclasses of lipoproteins. The patients who did not use the medication for at least $75 \%$ of the days were excluded from the treatment group. Those patients with less than 50\% adherence or who did not use the medication for at least 4 weeks when returning at the $12^{\text {th }}$ week became part of the control group (group C). The patients with an intermediary level of adherence to treatment were considered as lost and excluded from the study. Of the 44 postmenopausal patients who were effectively enrolled, 7 were included in group C because of the already cited reasons. Two patients did not return and 4 used the medication during $50 \%$ to $75 \%$ of the days; therefore, they were considered as lost. The group of hormone replacement therapy comprised 31 patients, 26 with combined estrogen-progestin therapy, and 5 with isolated estrogen therapy. Group C comprised 7 patients.

Right after arriving at the laboratory, the frasks with withdrawn blood were centrifuged for 15 minutes at $1,600 \mathrm{G}$ for plasma separation. The plasma was then frozen in a special freezer at the temperature of $-75^{\circ} \mathrm{C}$. Measurements of the subfractions of lipoproteins were performed at Wake Forest University School of Medicine, Winston-Salem, NC, USA, in a Brucker WM-250 spectrometer. The basis of the analysis through nuclear magnetic resonance is that, in plasma, each particle of lipoprotein, within a diameter band, irradiates a distinct signal of nuclear magnetic resonance, which is proportional to the total concentration of the lipid mass. Quantification is obtained through a 3-step process comprising measurement of the plasma lipid spectrum through nuclear magnetic resonance, followed by splitting, and computerized calculation using special software. The entire process lasts approximately 1 minute, and an excellent degree of accuracy and precision was demonstrated in validation tests. A strict concordance exists between distribution of the LDL and HDL subclasses determined by electrophoresis and nuclear magnetic resonance ${ }^{20-23}$. In addition to chylomicrons, this method quantifies 15 different subclasses of lipoproteins as follows: 6 subclasses of VLDL, 1 of IDL, 3 of LDL, and 5 of HDL, exploring natural differences of proton nuclear magnetic resonance spectra exhibited by lipoprotein particles of different sizes, without requiring reagents, and using minimum manipulation.

The significance level was $\leq 0.05$ in the 2-tailed test. Analysis of efficacy was performed for the patients who effectively used the medication. The basal differences between the groups, in regard to demographic and biochemical variables, were analyzed with the Student \# test for independent samples when continuous variables were considered, and with the chi-square test for categorical variables. For each major lipoprotein (VLDL, LDL, and HDL), the subfractions were grouped into large and small for analysis of their distribution. In regard to VLDLs, the $\mathrm{V}_{6}, \mathrm{~V}_{5}$, and $\mathrm{V}_{4}$ subfractions (corresponding to the largest VLDLs) constituted the large VLDL subgroup, and $\mathrm{V}_{3}, \mathrm{~V}_{2}$, and $\mathrm{V}_{1}$ (corresponding to the smallest VLDLs) constituted the small VLDL subgroup. In regard to LDLs, the $\mathrm{L}_{3}$ and $\mathrm{L}_{2}$ subfractions (corresponding to large, floating, and intermediate LDLs) constituted the large LDL group, and $\mathrm{L}_{1}$ (corresponding to small and dense LDLs) constituted the small LDL group. Of the $5 \mathrm{HDL}$ subfractions, $\mathrm{H}_{5}$ and $\mathrm{H}_{4}$ (corresponding to $\mathrm{HDL}_{2 \mathrm{~b}}$ and $\mathrm{HDL}_{2 \mathrm{a}}$ ) constituted the large $\mathrm{HDLs}$, and $\mathrm{H}_{3}, \mathrm{H}_{2}$, and $\mathrm{H}_{1}$ (corresponding to $\mathrm{HDL}_{3 \mathrm{a}}, \mathrm{HDL}_{3 \mathrm{~b}}$, and $\mathrm{HDL}_{3 \mathrm{c}}$ ) constituted the small HDL group. Values within each group of subfractions were transformed in percentage of the total sum of lipoprotein subfractions for analysis of their distribution. For analyzing the results of the variations of the profile of subfractions from the week 0 to week 12 , we used the Student $t$ test for samples paired for each group.

\section{Results}

Basal data related to age, years after menopause, race, 
weight, body mass index, blood pressure, reason for searching the outpatient care clinic of climacterium, alcohol ingestion, coronary risk factors, and use of medication are shown in table I and do not differ in the 2 groups.

During the 12-week follow-up, no significant change occurred in the mean weight of the patients in both groups. Two patients in the group using hormone replacement therapy and 1 patient in the control group started regular physical exercise practice $(\mathrm{p}=0.46)$.

Basal and final distribution profiles of lipoprotein subfractions in the different groups studied, according to grouping for analysis, are shown in table II. The corresponding variation of this distribution is depicted in figure 1 .

A significant increase in the proportion of the larger VLDL subfractions (large VLDLs comprising $\mathrm{V}_{6}, \mathrm{~V}_{5}$, and $\mathrm{V}_{4}$ ) occurred in regard to the smaller subfractions (small VLDLs comprising $\mathrm{V}_{3}, \mathrm{~V}_{2}$, and $\mathrm{V}_{1}$ ) in the hormone replacement therapy group $(\mathrm{p}<0.008)$. In this group, the proportion of larger particles of this lipoprotein increased from $47 \%$ to $57 \%$ in the 12 weeks of treatment, and the proportion of smaller particles decreased correspondingly from $53 \%$ to $43 \%$. GroupC showed no variation in the proportion of particles.

In regard to LDL subfractions, no significant variation in the proportion of large (corresponding to $\mathrm{L}_{3}$ and $\mathrm{L}_{2}$ ) and small (corresponding to $\mathrm{L}_{1}$ ) LDLs occurred in both groups during the 12 weeks of treatment.

\begin{tabular}{|c|c|c|c|}
\hline Basal characteristics & $\begin{array}{c}\text { Group C } \\
(\mathrm{n}=7)\end{array}$ & $\begin{array}{l}\text { Group HRT } \\
(\mathrm{n}=31)\end{array}$ & $\mathrm{p}$ \\
\hline Age in years, mean $\pm S D$ & $54 \pm 4.1$ & $53 \pm 6.2$ & 0.44 \\
\hline Years after menopause, mean \pm SD & $4.2 \pm 1.6$ & $4.3 \pm 3.7$ & 0.97 \\
\hline Race, number $(\%)$ & & & 1.00 \\
\hline White & $7(100)$ & $30(97)$ & \\
\hline Black & 0 & $1(3)$ & \\
\hline Weight in $\mathrm{kg}$, mean $\pm \mathrm{SD}$ & $69.3 \pm 11.7$ & $65.6 \pm 10.8$ & 0.43 \\
\hline Body mass index in $\mathrm{g} / \mathrm{m}^{2}$, mean $\pm \mathrm{SD}$ & $26.9 \pm 4.7$ & $26.2 \pm 4.4$ & 0.73 \\
\hline \multicolumn{4}{|l|}{ Blood pressure in $\mathrm{mm} \mathrm{Hg}$, mean $\pm \mathrm{SD}$} \\
\hline Systolic & $122 \pm 9.5$ & $121 \pm 14.8$ & 0.74 \\
\hline Diastolic & $77 \pm 7.5$ & $81 \pm 10.3$ & 0.40 \\
\hline Glucose in $\mathrm{mg} / \mathrm{dL}$, mean $\pm \mathrm{SD}$ & $87 \pm 11$ & $90 \pm 18$ & 0.71 \\
\hline $\begin{array}{l}\text { Reason for outpatient care clinic referral, } \\
\text { number }(\%)\end{array}$ & & & 1.00 \\
\hline Climacteric syndrome & $6(86)$ & $28(90)$ & \\
\hline Preventive treatment for osteoporosis & $1(14)$ & $3(10)$ & \\
\hline \multicolumn{4}{|l|}{ Coronary risk factors, number $(\%)$} \\
\hline Hypertension & $4(57)$ & $11(35)$ & 0.40 \\
\hline Diabetes & 0 & $1(3)$ & 1.00 \\
\hline Current smoker & $1(14)$ & $5(16)$ & 1.00 \\
\hline Obesity - BMI $>30 \mathrm{~kg} / \mathrm{m}^{2 *}$ & $2(29)$ & $9(29)$ & 1.00 \\
\hline Sedentary lifestyle & $4(57)$ & $20(65)$ & 1.00 \\
\hline Family history of ischemic heart disease & $1(14)$ & $4(13)$ & 1.00 \\
\hline Total cholesterol $>240 \mathrm{mg} / \mathrm{dL}$ & $1(14)$ & $7(23)$ & 1.00 \\
\hline LDL-cholesterol $>160 \mathrm{mg} / \mathrm{dL}$ & $1(14)$ & $5(16)$ & 1.00 \\
\hline HDL-cholesterol $<35 \mathrm{mg} / \mathrm{dL}$ & $2(28)$ & $3(10)$ & 0.22 \\
\hline Triglycerides $>200 \mathrm{mg} / \mathrm{dL}$ & $1(14)$ & $4(13)$ & 1.00 \\
\hline \multicolumn{4}{|l|}{ Alcohol consumption, number (\%) } \\
\hline Occasional or frequent & 0 & 0 & \\
\hline \multicolumn{4}{|l|}{ Medication use, number (\%) } \\
\hline Diuretics & $3(43)$ & $4(13)$ & 0.09 \\
\hline Beta-blockers & 0 & $3(10)$ & 1.00 \\
\hline Corticosteroids & $1(14)$ & 0 & 0.18 \\
\hline
\end{tabular}

In regard to HDLs, a significant increase in the proportion of large HDLs (corresponding to $\mathrm{H}_{5}$ and $\mathrm{H}_{4}$, or $\mathrm{HDL}_{2 \mathrm{~b}}$ and $\mathrm{HDL}_{2 \mathrm{a}}$ ) occurred as compared with small HDLs (corresponding to $\mathrm{H}_{3}, \mathrm{H}_{2}$, and $\mathrm{H}_{1}$, or $\mathrm{HDL}_{3 \mathrm{a}}, \mathrm{HDL}_{3 \mathrm{~b}}$, and $\mathrm{HDL}_{3 \mathrm{c}}$ ) in the group of hormone replacement therapy $(\mathrm{p}<0.025)$. This resulted from an increase in the larger subfractions from $46 \%$ to $50 \%$ and correspondingly reduction in the smaller subfractions from $54 \%$ to $50 \%$. Group C showed no variation in the proportion of particles.

Analyzing the changes occurring in plasma levels of VLDL subclasses to verify how alterations in proportion occurred after hormone replacement therapy, we observed a $36 \%$ increase in the larger VLDL subfractions $(\mathrm{p}<0.004)$ concomitantly with a $15 \%$ reduction in the smaller VLDL subfractions ( $\mathrm{p}<0.036)$. In regard to HDL, a $17 \%$ increase in the larger subfractions $(\mathrm{p}<0.002)$ occurred with no change in the smaller subfractions (Table III and fig. 2).

\section{Discussion}

Even though the clinical relevance of the heterogeneity of the lipoprotein subfractions has been difficult to assess because of the extremely laborious nature of the methods for determining the subfractions of lipoproteins, differences in association with coronary heart disease suggest that data on lipoprotein subfractions may improve the evaluation of coronary risk. This situation is similar to

\begin{tabular}{|c|c|c|c|c|c|c|}
\hline \multicolumn{7}{|c|}{$\begin{array}{l}\text { Table II - Distribution of lipoprotein subfractions (\% of total } \pm \\
\text { standard deviation) in the two groups }\end{array}$} \\
\hline \multirow[t]{2}{*}{ Groups of subfraction } & \multicolumn{3}{|c|}{$\begin{array}{l}\text { Group C } \\
(\mathrm{n}=7)\end{array}$} & \multicolumn{3}{|c|}{$\begin{array}{l}\text { Group HRT } \\
\qquad(\mathrm{n}=31)\end{array}$} \\
\hline & \multicolumn{3}{|c|}{ Week 0Week 12 p } & \multicolumn{2}{|c|}{ Week 0 Week 12} & \multirow{2}{*}{$\frac{p}{0.008^{*}}$} \\
\hline Large VLDLs & $51 \pm 15$ & $50 \pm 6$ & 0.83 & $47 \pm 18$ & $57 \pm 15$ & \\
\hline Small VLDLs & $49 \pm 15$ & $50 \pm 6$ & 0.83 & $53 \pm 18$ & $43 \pm 15$ & $0.008^{*}$ \\
\hline Large LDLs & $67 \pm 21$ & $65 \pm 22$ & 0.69 & $80 \pm 17$ & $79 \pm 17$ & $0.814^{*}$ \\
\hline Small LDLs & $33 \pm 21$ & $35 \pm 22$ & 0.69 & $20 \pm 17$ & $21 \pm 17$ & $0.814^{*}$ \\
\hline Large HDLs & $37 \pm 23$ & $37 \pm 22$ & 0.75 & $46 \pm 19$ & $50 \pm 31$ & $0.03^{*} 5$ \\
\hline Small HDLs & $63 \pm 23$ & $63 \pm 22$ & 0.75 & $54 \pm 22$ & $50 \pm 21$ & $0.03^{*} 5$ \\
\hline \multicolumn{7}{|c|}{$\begin{array}{l}{ }^{*} \mathrm{p} \leq 0.05 \text {; Week } 0 \text { - basal measurement; Week } 12 \text { - measurement after } 12 \\
\text { weeks ; p- Student } t \text { test for paired variables. }\end{array}$} \\
\hline
\end{tabular}

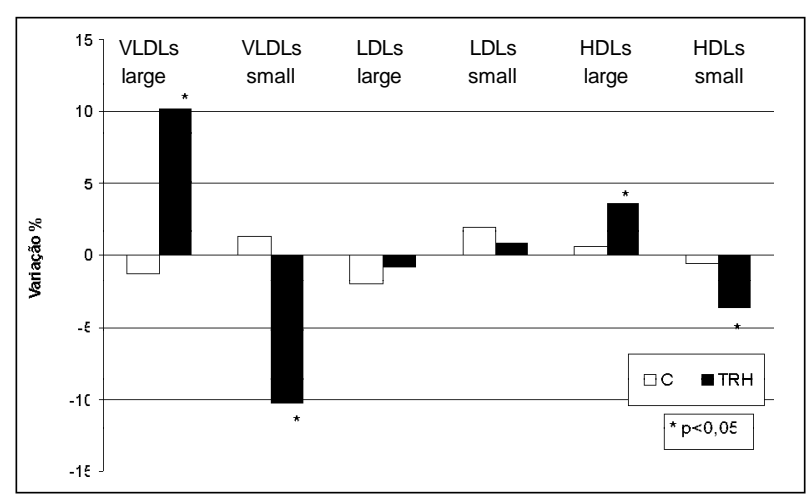

Fig. 1 - Variação média porcentual da distribuição das subfrações de lipoproteínas entre a $12^{\mathrm{a}}$ semana e a basal nos dois grupos. 
that observed in the ' 50 s and ' 60 s, when data on cholesterol levels of lipoproteins could better predict the coronary risk than the total cholesterol serum levels isolated.

Most methods usually used for separating and quantifying subfractions of lipoproteins include techniques such as ultracentrifugation, electrophoresis, or chromatography, which are very laborious and slow and, therefore, become unfeasible for clinical research on a large scale or for assessment of coronary risk in the general population. A recently validated method that employs nuclear magnetic resonance spectroscopy is a more precise, rapid, and less expensive alternative as compared with the already existing methods for assessing and handling coronary risk based on measurements of subfractions ${ }^{21}$. This technique explores the natural spectral difference that exists between the subfractions of each lipoprotein, depending only on the size of the particles. The technique avoids the steps of physical separation, the use of reagents, and employs a totally automated process, thus providing a high rate of efficiency and precision in the evaluation. This allows the simultaneous calculation of the concentrations of each of the 16 lipoprotein subclasses, 1 being chylomicron, 6 of VLDL, 1 of IDL, 3 of LDL, and 5 of HDL ${ }^{24}$.

Despite the great methodological difference between nuclear magnetic resonance and the other methods used to quantify lipoproteins, some studies have shown a proximity between the sizes of LDL and HDL particles measured by nuclear magnetic resonance and by electrophoresis with gel gradient ${ }^{20,25}$. As no appropriate and high-resolution

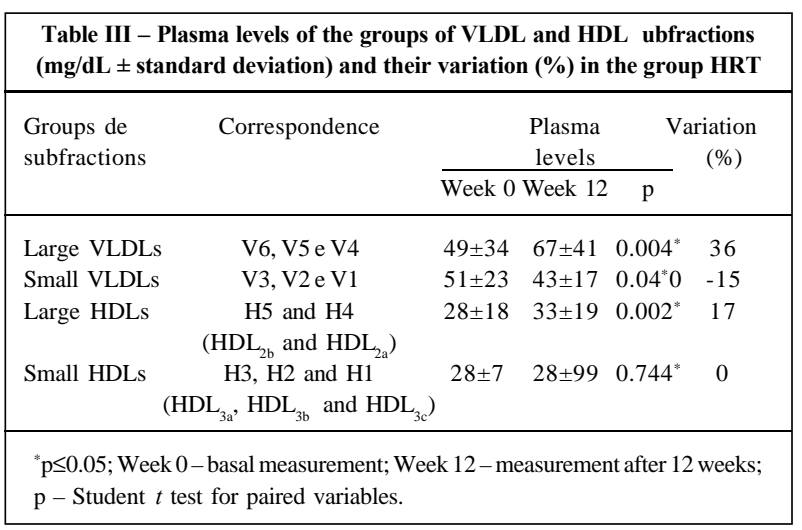

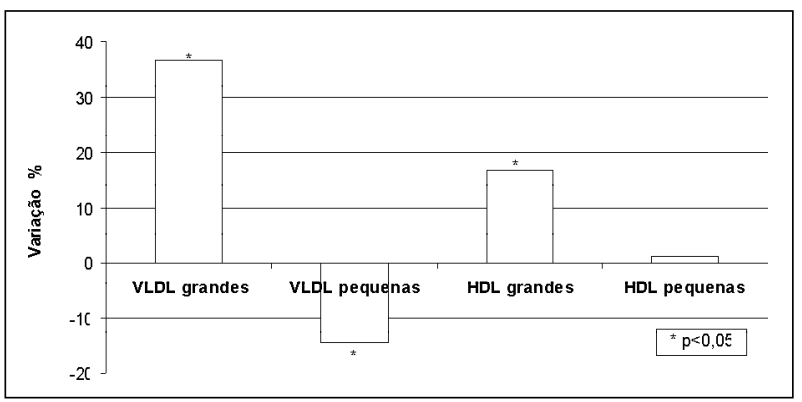

Fig. 2 - Variação média porcentual dos níveis médios das subfrações de lipoproteínas entre a $12^{\mathrm{a}}$ semana e a basal no grupo TRH. technique was available for measuring VLDL subfractions, only a few studies could separate VLDL subfractions that effectively represented distinct subclasses ${ }^{21,26,27}$. Therefore, comparison of nuclear magnetic resonance with other methods is impaired in this regard.

In our study, we observed an increase in the proportio$n$ of larger VLDLs as compared with that of smaller VLDLs due to an increase in the level of larger particles and a concomitant reduction in smaller particles. Another study ${ }^{28}$ using the same method has already shown a reduction in the smaller VLDL subfractions after hormone replacement therapy. In the literature, only a few studies report the effect of hormone replacement therapy on the profile of VLDL subfractions, because of the difficulties in separating these subfractions by the conventional techniques used prior to nuclear magnetic resonance. Estrogens seem to increase hepatic synthesis of VLDL-triglycerides forming particularly large VLDLs, rich in triglycerides, acting directly upon the hepatocyte ${ }^{29}$. Most VLDLs are withdrawn from circulation directly by the liver without being metabolized to small VLDL or LDL. In this way, the elevation in triglycerides induced by estrogens is supposed to be less harmful than that present in other clinical situations ${ }^{30}$. The increase in the proportion of larger VLDL subfractions was similar in patients using isolated or combined estrogen therapy, which could be expected because progestins do not block the metabolic effects of estrogen in the hepatocyte. Whether large VLDLs actually produce small and dense LDLs ${ }^{22}$ in case of no inhibition of the hepatic lipase by estrogen, with the increase in VLDLs caused by hormone replacement therapy, a greater amount of small and dense, more atherogenic, LDLs could be produced, which in reality does not occur ${ }^{30}$.

No change was observed in the distribution of LDL subfractions in the present study. Even though an induction to a predominance of larger and less atherogenic (pattern A) particles could be expected because of the supposed cardioprotective effect, a few studies have found an opposite trend ${ }^{17,31}$. This action of reducing the larger and less dense LDLs in detriment to the smaller and denser particles could be due to the fact that the former are more easily captured by hepatic receptors of LDL, whose action is stimulated by estrogens ${ }^{32}$.

The increase in the proportion of larger subfractions of HDL found agrees with data in the literature ${ }^{28,33}$. An increase in the proportion of larger particles $\left(\mathrm{H}_{5}\right.$ and $\mathrm{H}_{4}$, corresponding to $\mathrm{HDL}_{2 \mathrm{~b}}$ and $\mathrm{HDL}_{2 \mathrm{a}}$ ) as compared with that of smaller particles $\left(\mathrm{H}_{3}, \mathrm{H}_{2}\right.$, and $\mathrm{H}_{1}$, corresponding to $\mathrm{HDL}_{3 \mathrm{a}}, \mathrm{HDL}_{3 \mathrm{~b}}$, and $\mathrm{HDL}_{3 \mathrm{c}}$ ) occurred due to an increase in the larger subfractions with no changes in the levels of the smaller fractions, which is in accordance with data in the literature ${ }^{29,30,34,35}$. The catabolism of $\mathrm{HDL}_{2}$ is mediated by hepatic lipase, a lipolytic enzyme present in the endothelial cells lining the hepatic sinusoids and highly specific for $\mathrm{HDL}_{2 \mathrm{~b}}$, the larger subfraction of $\mathrm{HDL}^{36}$. The effects of sexual steroids on the levels of HDL, particularly $\mathrm{HDL}_{2}$, are believed to be mediated by changes in the activity of hepatic lipase ${ }^{33}$, because the increase in $\mathrm{HDL}_{2}$ with the use of estrogen is associated with a 
reduction in the activity of this enzyme. On the other hand, addition of a progestin has an inverse effect, which is more marked as the androgenic effect increases (the effect of medroxyprogesterone is low), and it may even reverse the increase in $\mathrm{HDL}_{2}$ and the reduction in the activity of the hepatic lipase ${ }^{34}$.

Clinical significance of the changes imposed by hormone replacement therapy in the profile of lipoprotein subfractions should be better evaluated in further larger clinical trials.

In the present study, in addition to the possibility of potential contamination of the cohort model by confounding factors, the control group was composed of patients not adhering to the treatment. As all patients starting hormone replacement therapy in the outpatient care clinics had precise medical indications for it (climacteric symptoms or osteoporosis), from the ethical point of view they were not amenable to being directly allocated to the control group.
Even though all basal variables observed were not significantly different in both groups, a tendency to a higher prevalence of hypertension occurred in the control group, as did HDL below $35 \mathrm{mg} / \mathrm{dL}$ and the use of diuretics. This and the known fact that the adherence factor in many studies may be associated with healthier habits may have interfered with the final result of the study.

\section{Aknowledgement}

We thank the Laboratório Weinmann from Porto Alegre for the biochemical measurements performed and the shipping of samples to the USA; the Department of Biochemistry and Department of Comparative Medicine of Wake Forest University School of Medicine, Winston-Salem, NC, for the analysis of lipoproteins with nuclear magnetic resonance; and the Laboratório Wyeth, for providing the medication used in the study.

\section{References}

1. Hulley S, Grady D, Bush T, et al. Randomized trial of estrogen plus progestin for secondary prevention of coronary heart disease in postmenopausal women. JAMA 1998; 280: 605-13.

2. Herrington D. The Estrogen Replacement and Atherosclerosis in older women (ERA) Trial, Late-Breaking Clinical Trial Results. American College of Cardiology $49^{\text {th }}$ Annual Scientific Session, Anaheim, 2000.

3. Grodstein F, Stampfer M. The epidemiology of coronary heart disease and estrogen replacement in postmenopausal women. Prog Cardiovasc Dis 1995; 38: 199-210.

4. Manson JE. Postmenopausal hormone therapy and atherosclerotic disease. Am Heart J 1994; 128: 1337-43.

5. Barrett-Connor E. Heart disease in women. Pharmacologic Fertil Steril 1994; 62(suppl.2): 127S-32S

6. Thorneycroft IH. Practical aspects of hormone replacement therapy. Prog Cardiovasc Dis 1995; 38: 243-54.

7. Grodstein F, Stampfer MJ, Manson JE, et al. Postmenopausal estrogen and progestin use and the risk of cardiovascular disease. N Engl J Med 1996; 335: 453-61.

8. Grodstein F, Stampfer MJ, Colditz GA, et al. Postmenopausal hormone therapy and mortality. N Engl J Med 1997; 336: 1769-75.

9. Gotto AM Jr. Postmenopausal hormone-replacement therapy, plasma lipoprotein[a], and risk for coronary heart disease. J Lab Clin Med 1994; 123: 800-3.

10. Austin M, Breslow J, Hennekens C, Buring J, Willett W, Krauss R. Low-density lipoprotein subclass patterns and risk of myocardial infarction. JAMA 1988; 260: 1917-21.

11. Superko HR, Haskell WL, Krauss RM. Association of lipoprotein subclass distribution with use of selective and non-selective beta-blocker medications in patients with coronary heart disease. Atherosclerosis 1993; 101: 1-8.

12. Austin M, Mykkanen L, Kuusisto J, et al. Prospective study of small LDLs as a risk factor for non-insulin dependent diabetes mellitus in elderly men and women. Circulation 1995; 92: 1770-8.

13. Krauss RM, Blanche PJ. Detection and quantification of LDL subfractions. Curr Opin Lipidol 1992; 3: 377-83.

14. Austin A, Hokanson J, Brunzell J. Characterization of low-density lipoprotein subclasses: methodologic approaches and clinical relevance. Curr Opin Lipidol 1994; 5: 395-403.

15. Tornvall P, Karpe F, Proudler A, et al. High-density lipoprotein: relations to metabolic parameters and severity of coronary artery disease. Metabolism 1996; 45: $1375-82$.

16. Johansson J, Walldius G, Carlson LA. Close correlation between high-density lipoprotein and triglycerides in normotriglyceridaemia. J Intern Med 1992; 232: 43-51.
17. Seed M, Crook D. Post-menopausal hormone replacement therapy, coronary heart disease and plasma lipoproteins. Curr Opin Lipidol 1994; 5: 48-58.

18. Paganini-Hill A. Estrogen replacement therapy and stroke. Prog Cardiovasc Dis 1995; 38: 223-42.

19. Bagatell CJ, Bremner WJ. Androgen and progestagen effects on plasma lipids. Prog Cardiovasc Dis 1995; 38: 255-71.

20. Otvos JD, Jeyarajah EJ, Bennett D, Krauss RM. Development of a proton nuclear magnetic resonance spectroscopic method for determining plasma lipoprotein concentrations and subspecies distributions from a single, rapid measurement. Clin Chem 1992; 38: 1632-8.

21. Otvos J, Jeyarajah E, Bennet D. A spectroscopic approach to lipoprotein subclass analisys. J Clin Ligand Assay 1996; 19: 184-9.

22. Freedman DS, Otvos JD, Jeyarajah EJ, Barboriak JJ, Anderson AJ, Walker JA. Relation of lipoprotein subclasses as measured by proton nuclear resonance spectroscopy to coronary heart disease. Arterioscler Thromb Vasc Biol 1998; 18: 1046-53.

23. Otvos J. Measurement of triglyceride-rich lipoprotein by NMR spectroscopy. Clin Cardiol 1999; 22: 21-7.

24. Parsons SK, Skapek SX, Neufeld EJ, et al. Asparaginase-associated lipid abnormalities in children with acute lymphoblastic leukemia. Blood 1997; 89: 1886-95.

25. Ala-Korpela M, Korhonen A, Keisala J, et al. 1H NMR-based absolute quantitation of human lipoproteins and their lipid contents directly from plasma. J Lipid Res 1994; 35: 2292-304.

26. Otvos JD. Measurement of lipoprotein subclass profiles by NMR spectroscopy. In: Rifai N, Warnick R, Dominiczak M, eds. Handbook of Lipoprotein Testing. Washington DC: AACC Press, 1997: 497-508.

27. Zhao SP, Bastiaanse EM, Hau MF, et al. Separation of VLDL subfractions by density gradient ultracentrifugation. J Lab Clin Med 1995; 125: 641-9.

28. Tangney CC, Mosca L, Otvos JO, et al. Hormone replacement therapy in postmenopausal women increases HDL particle size. Circulation 1998; Supplement (abstracts from the $71^{\text {st }}$ Scientific Sessions. November, 1998): 32.

29. Nabulsi AA, Folsom AR, White A, et al. Association of hormone-replacement therapy with various cardiovascular risk factors in postmenopausal women. $\mathrm{N}$ Engl J Med 1993; 328: 1069-75.

30. Walsh B, Schiff I, Rosner B, Greenberg L, Ravnikar V, Sacks F. Effects of postmenopausal estrogen replacement on the concentrations and metabolism of plasma lipoproteins. N Engl J Med 1991; 325: 1196-204.

31. Lahdenperä S, Puolakka J, Pyörälä T, Luotola H, Taskinen MR. Effects of postmenopausal estrogen/progestin replacement therapy on LDL particles; comparison of transdermal and oral treatment regimens. Atherosclerosis 1996; 122: 153-62.

32. Griffin B, Packard C. Metabolism of VLDL and LDL subclasses. Curr Opin Lipidol 1994; 5: 200-6. 
33. Thuren TY, Rudel LL, Brinton EA, et al. Effect of estrogen on hepatic lipase and HDL particle size in post-menopausal women. from the $71^{\text {st }}$ Scientific Sessions. November, 1998): Circulation 1998; (Suppl.): 2377.

34. Tikkanen M, Nikkila E, Kuusi T, Sipinen S. High density lipoprotein-2 and hepatic lipase: reciprocal changes produced by estrogen and norgestrel. J Clin Endocrinol Metab 1982; 54: 1113-7.
35. Sotelo MM, Jonhson SR. The effects of hormone replacement therapy on coronary heart disease. 1997; 26: 313-326

36. Moriguchi EH, Fusegawa Y, Tamachi H, Goto Y. Age-related modifications in high density lipoprotein particle size and chemical composition - effects of reduction in hepatic lipase activity with age. Asian Med J 1990; 33: 641-50.



Paranapiacaba - São Paulo
Mucio Tavares de Oliveira Jr
Seção de fotografias artísticas Cícero Piva de Albuquerque

Contribuições e correspondência: Unidade Clínica de Aterosclerose - Av. Dr. Eneas de Carvalho Aguiar, 44 Cep: 05403-000 São Paulo e-mail: dclcicero@incor.usp.br 